\title{
Cardamonin enhances the anti-proliferative effect of cisplatin on ovarian cancer
}

\author{
PEIGUANG NIU, DAOHUA SHI, SHUSHENG ZHANG, YANTING ZHU and JINTUO ZHOU \\ Department of Pharmacy, Fujian Provincial Maternity and Children Hospital, \\ Affiliated Hospital of Fujian Medical University, Fuzhou, Fujian 350001, P.R. China
}

Received August 15, 2016; Accepted September 9, 2017

DOI: $10.3892 / \mathrm{ol} .2018 .7743$

\begin{abstract}
The mammalian target of rapamycin (mTOR) is well-known as a promising therapeutic target in various cancer cells. mTOR activation decreases the sensitivity of ovarian cancer to cisplatin. Cardamonin inhibits the proliferation of various cancer cells by mTOR suppression. The present study examined whether cardamonin combined with cisplatin is efficacious for the anti-proliferation of ovarian cancer cells. The anti-proliferative effect was determined by MTT and cell cycle assays. Activation of the mTOR signal pathway and the expression of anti-apoptotic proteins were evaluated by western blot analysis. Cardamonin significantly enhanced the effects of cisplatin on cell proliferation and cell cycle progression. The expression of B cell lymphoma-2, X-linked inhibitor of apoptosis protein and Survivin was significantly decreased following combination treatment. Furthermore, the activation of mTOR and its downstream $70 \mathrm{kDa}$ ribosomal protein S6 kinase was inhibited by cardamonin. These results demonstrated that the combinatorial effects of cardamonin and cisplatin on anti-proliferation were enhanced by suppressing the expression of anti-apoptotic proteins and activation of mTOR in ovarian cancer cells.
\end{abstract}

\section{Introduction}

Ovarian cancer is a major cause of gynecological malignancy-associated mortality worldwide. The majority of patients are diagnosed with epithelial ovarian cancer at the advanced stage and the 5-year survival rate is $20-40 \%$ (1). Platinum-based adjuvant chemotherapy following cytoreductive surgery is commonly used for treatment of ovarian cancer, which is initially effective in a high percentage of cases (2). However, an increasing number of patients eventually relapse

Correspondence to: Professor Daohua Shi, Department of Pharmacy, Fujian Provincial Maternity and Children Hospital, Affiliated Hospital of Fujian Medical University, 18 Daoshan Road, Fuzhou, Fujian 350001, P.R. China

E-mail: shidh@yeah.net

Key words: cardamonin, cisplatin, mammalian target of rapamycin, apoptosis, ovarian cancer due to the decreased sensitivity to cisplatin $(3,4)$. Therefore, novel therapeutic strategies are required to increase the sensitivity of cancer cells to cisplatin.

Chemotherapeutic drug-induced apoptosis is usually disturbed by the anti-apoptotic proteins, including B cell lymphoma-2 (Bcl-2), X-linked inhibitor of apoptosis protein (XIAP) and Survivin (5). Bcl-2 regulates programmed cell death in various cancer cell lines. It exerts a survival function in response to a wide range of apoptotic stimuli and inhibits the release of mitochondrial cytochrome $c(6)$. XIAP is well known as a direct inhibitor of apoptosis, which binds to caspase-3, -7 and -9 and prevents their activities (7). Survivin interferes with apoptosis by inhibiting the activity of caspases or via interaction with other regulators. It has been demonstrated that Survivin binds to XIAP and inhibits the activation of caspase-9 (8). The overexpression of these proteins is involved in the insensitivity of epithelial ovarian cancer cells to cisplatin (9-11).

Mammalian target of rapamycin (mTOR) activation is essential in the development of cisplatin insensitivity in ovarian cancer cells. It was reported that the phosphorylation level of mTOR was higher in cisplatin-insensitive clear-cell ovarian carcinoma cells compared with in cisplatin-sensitive cells $(12,13)$. mTOR also performs a key role in the modulation of cisplatin-induced apoptotic cell death. Cisplatin activates the mTOR survival pathway in epithelial and clear-cell carcinoma ovarian cancer cells, which may counteract cisplatin-induced apoptosis and in turn lead to cisplatin resistance $(14,15)$. The mTOR inhibitors, rapamycin and its analogs, including everolimus, efficiently enhance the therapeutic efficacy of platinum in clear-cell ovarian carcinoma cells $(16,17)$. Therefore, mTOR is a promising therapeutic target for the treatment of ovarian cancer when combined with cisplatin.

Cardamonin is a natural chalcone compound, which increases cell apoptosis in nasopharyngeal carcinoma, prostate cancer and triple negative breast cancer cells and induces autophagy in colorectal carcinoma cells (18-21). Cardamonin inhibits a number of signaling pathways, including c-Jun $\mathrm{N}$-terminal kinase, nuclear factor- $\kappa \mathrm{B}$, and signal transducer and activator of transcription $3(21,22)$. Combined with doxorubicin, cardamonin sufficiently prevents the enrichment of drug-resistant triple negative breast cancer stem cells and retards tumor growth (23). It may also increase the anti-proliferative effect of cisplatin in cervical carcinoma, 
hepatocellular carcinoma, prostate cancer and colon cancer cells (24). However, the underlying mechanism has not been previously studied. Our previous studies demonstrated that cardamonin inhibits the proliferation, angiogenesis and metastasis of non-small cell lung carcinoma cells, epithelial ovarian cancer cells and Lewis lung carcinoma cells by inhibition of mTOR activation (25-27). In the current study, the therapeutic potency of cardamonin combined with cisplatin in ovarian cancer was evaluated and the underlying mechanism was investigated.

\section{Materials and methods}

Chemical reagents. Solutions and supplements for cell culture were purchased from Gibco (Thermo Fisher Scientific, Inc., Waltham, MA, USA). Cardamonin, cisplatin, dimethyl sulfoxide (DMSO) and MTT were purchased from Sigma-Aldrich (Merck KGaA, Darmstadt, Germany). Antibodies against mTOR (cat. no. 2972; dilution, 1:1,000), phospho-mTOR (Ser 2448; cat. no. 2971; dilution, 1:1,000), $70 \mathrm{kDa}$ ribosomal protein S6 kinase (p70S6K; cat. no. 9202; dilution, 1:1,000), phospho-p70S6K (Thr 389; cat. no. 9205; dilution, 1:1,000), Bcl-2 (cat. no. 2872; dilution, 1:1,000), Survivin (cat. no. 2803; dilution, 1:1,000), XIAP (cat. no. 2042; dilution, 1:1,000) and actin (cat. no. 4967; dilution, 1:1,000), and the secondary antibody (anti-rabbit IgG, horseradish peroxidase-linked antibody; cat. no. 7074; dilution, 1:2,000) were purchased from Cell Signaling Technologies, Inc. (Danvers, MA, USA). The cell cycle assay kit was from BD Biosciences (San Jose, CA, USA).

Cell culture. Epithelial ovarian cancer SKOV3 and A2780 cells were obtained from Wuhan Boster Bio-Engineering Ltd. Co. (Wuhan, China), and cultured, at $37^{\circ} \mathrm{C}$ in a saturated humidity incubator with an atmosphere containing $5 \% \mathrm{CO}_{2}$, in McCoy's 5A and high glucose Dulbecco's modified Eagle's medium (DMEM; Gibco; Thermo Fisher Scientific, Inc.), respectively. The media was supplemented with $10 \%$ fetal bovine serum (FBS; Gibco; Thermo Fisher Scientific, Inc.), penicillin $(100 \mathrm{U} / \mathrm{ml})$ and streptomycin $(100 \mu \mathrm{g} / \mathrm{ml})$ (HyClone; GE Healthcare Life Sciences, Little Chalfont, UK).

Cell viability assay. MTT assay was used to analyze the effect of cardamonin on cell viability as previously described (28). Cells were cultured overnight at $37^{\circ} \mathrm{C}$ in a saturated humidity incubator with an atmosphere containing $5 \% \mathrm{CO}_{2}$ in 96 -well plates $\left(5 \times 10^{3}\right.$ cells/well). Cell viability was assessed following the addition of cardamonin and cisplatin at the indicated concentrations for $48 \mathrm{~h}$ in medium containing 10\% FBS. Surviving cells were assessed using a microplate reader (Bio-Rad Laboratories, Inc., Hercules, CA, USA) for the determination of the absorbance at $570 \mathrm{~nm}$ of the DMSO-dissolved formazan product following the addition of MTT $(5 \mathrm{mg} / \mathrm{ml})$ for $4 \mathrm{~h}$. Five independent experiments were performed.

Clonogenic survival assay. The clonogenic survival assay was performed as previously described (28). Cells ( $1 \times 10^{3} /$ well) were seeded on 6-well tissue culture plates in medium containing $10 \%$ FBS. The cells were cultured overnight at $37^{\circ} \mathrm{C}$ in a saturated humidity incubator with an atmosphere containing $5 \% \mathrm{CO}_{2}$, and then treated with cisplatin in the presence or absence of cardamonin for $48 \mathrm{~h}$, followed by two washes in McCoy's 5A and DMEM, respectively. The cells were then cultured in medium containing 10\% FBS and allowed to proliferate for 7 days. Cells were fixed with ethanol (75\%) at room temperature for $15 \mathrm{~min}$ and stained by $1 \%$ crystal violet at room temperature for $60 \mathrm{~min}$. Colonies ( $>30$ cells/colony) were counted with a Leica DMIL LED microscope (magnification, x200; Leica Microsystems GmbH, Wetzlar, Germany) for each group to generate survival rate in triplicate wells. Five independent experiments were performed.

Cell cycle assay. Cell cycle distribution was determined by flow cytometry based on DNA content measurement of nuclei, stained with propidium iodide (PI). Following treatment with cisplatin in the presence or absence of cardamonin for $48 \mathrm{~h}$, cells were the washed with cold PBS and harvested by centrifugation at $400 \mathrm{x}$ g at room temperature for $5 \mathrm{~min}$. Cells were then fixed in cold ethanol $(70 \%)$ overnight at $4^{\circ} \mathrm{C}$. Next, the cells were stained with $50 \mu \mathrm{g} / \mathrm{ml}$ PI and $10 \mu \mathrm{g} / \mathrm{ml}$ RNase A (BD Biosciences, San Jose, CA, USA) in the dark at room temperature for $30 \mathrm{~min}$ in the dark. Cell cycle distribution was analyzed by flow cytometry (BD Biosciences). Results were calculated by the Mod Fit LT software version 2.0 (BD Biosciences). Five independent experiments were performed.

Western blot analysis. Treated with indicated drugs for $48 \mathrm{~h}$, cells were washed with ice-cold PBS twice and lysed in radioimmunoprecipitation assay lysis buffer $(20 \mathrm{mM}$ Tris- $\mathrm{HCl}$ (pH 7.5), 150 mM NaCl, 1 mM Na 2 EDTA, 1 mM EGTA, $1 \%$ NP-40, $1 \%$ sodium deoxycholate, $2.5 \mathrm{mM}$ sodium pyrophosphate, $1 \mathrm{mM}$ beta-glycerophosphate, $1 \mathrm{mM} \mathrm{Na}_{3} \mathrm{VO}_{4}$ and $1 \mu \mathrm{g} / \mathrm{ml}$ leupeptin) with the addition of $1 \mathrm{mM}$ phenylmethylsulfonyl fluoride for $20 \mathrm{~min}$ at $4^{\circ} \mathrm{C}$. Lysates were centrifuged at $15,000 \mathrm{x} \mathrm{g}$ at $4^{\circ} \mathrm{C}$ for $20 \mathrm{~min}$, and protein concentrations of the supernatants were determined using a bicinchoninic acid protein assay reagent. Proteins $(40 \mu \mathrm{g})$ were separated by $6-12 \%$ SDS-PAGE and transferred to polyvinylidene difluoride membranes. The membranes were blocked with $5 \%$ bovine serum albumin (Cell Signaling Technologies, Inc.) in $1 \mathrm{X}$ TBS-Tween 20 for $1 \mathrm{~h}$ at room temperature and then incubated overnight at $4{ }^{\circ} \mathrm{C}$ with the following primary antibodies: mTOR (cat. no. 2972; dilution, 1:1,000), Ser 2448 (cat. no. 2971; dilution, 1:1,000), p70S6K (cat. no. 9202; dilution, 1:1,000), Thr 389 (cat. no. 9205; dilution, 1:1,000), Bcl-2 (cat. no. 2872; dilution, 1:1,000), Survivin (cat. no. 2803; dilution, 1:1,000), XIAP (cat. no. 2042; dilution, 1:1,000) and actin (cat. no. 4967; dilution, 1:1,000) all purchased from Cell Signaling Technologies, Inc. Immunoblots were visualized with horseradish peroxidase-conjugated goat anti-rabbit immunoglobulin (Cell Signaling Technologies, Inc.; cat. no. 7074; dilution, $1: 2,000)$ at room temperature for $1 \mathrm{~h}$ using enhanced chemiluminescence (GE Healthcare Life Sciences) and exposure to X-ray film to produce bands within the linear range. The protein purity was evaluated by densitometry analysis using the Quantity One software version 4.6.2 (Bio-Rad Laboratories, Inc.). Three independent experiments were performed.

Statistical analysis. All data are expressed as the mean \pm standard deviation. Statistical analysis was performed with SPSS version 16.0 software (SPSS, Inc., Chicago, IL, 
A

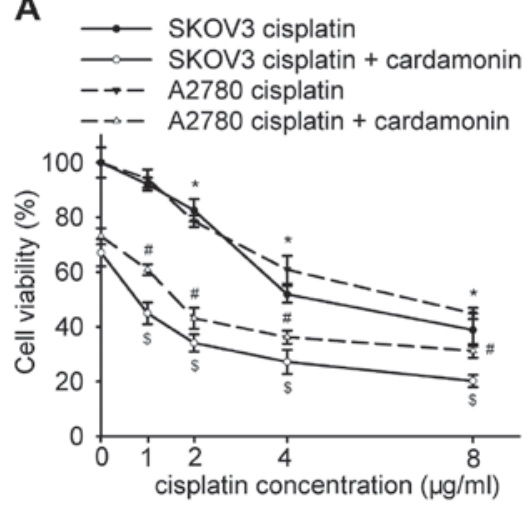

B

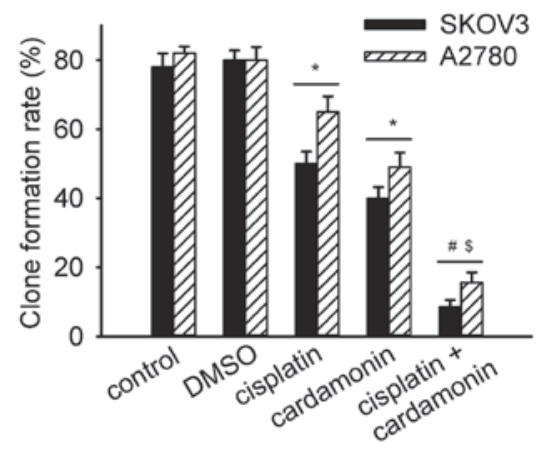

Figure 1. Cardamonin enhanced the anti-proliferative effect of cisplatin in SKOV3 and A2780 cells. (A) SKOV3 and A2780 cells were treated with 1, 2, 4, $8 \mu \mathrm{g} / \mathrm{ml}$ of cisplatin in the presence or absence of $20 \mu \mathrm{M}$ of cardamonin for $48 \mathrm{~h}$, and an MTT assay was performed ( $\mathrm{n}=5$ ). Data are presented as the mean \pm SD. ${ }^{*} \mathrm{P}<0.05$ vs. control; ${ }^{"} \mathrm{P}<0.01$ vs. the corresponding group treated with cisplatin alone in A2780 cells; ${ }^{\$} \mathrm{P}<0.01$ vs. the corresponding group treated with cisplatin alone in SKOV3 cells. (B) SKOV3 and A2780 cells $\left(1 \times 10^{3}\right)$ were treated with cardamonin $(20 \mu \mathrm{M})$, cisplatin $(2 \mu \mathrm{g} / \mathrm{ml})$ or the combination of the two agents for $48 \mathrm{~h}$, and then cells were processed for clonogenic survival assay $(\mathrm{n}=5)$. Data are presented as the mean $\pm \mathrm{SD}$. ${ }^{*} \mathrm{P}<0.05$ vs. control; ${ }^{*} \mathrm{P}<0.01 \mathrm{vs}$. cisplatin; ${ }^{\$} \mathrm{P}<0.01$ vs. cardamonin. SD, standard deviation; DMSO, dimethyl sulfoxide.
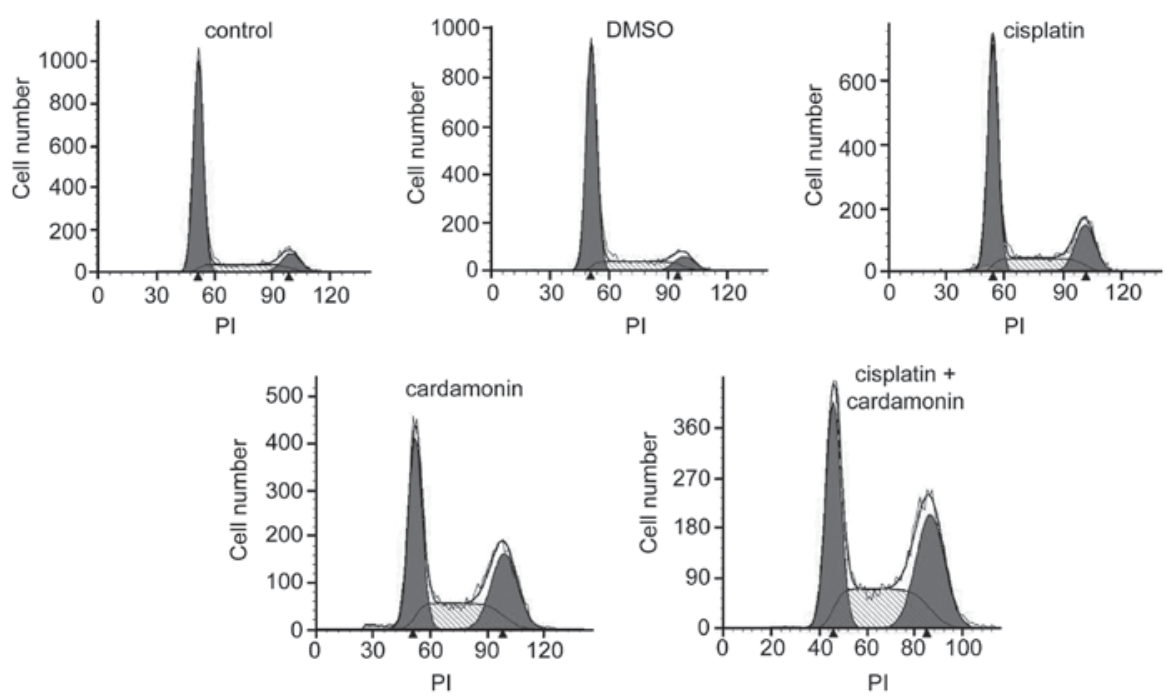

Figure 2. Cardamonin and cisplatin induced cell cycle arrest in G2/M phase in SKOV3 cells. SKOV3 cells were treated with cardamonin (20 $\mu \mathrm{M})$, cisplatin $(2 \mu \mathrm{g} / \mathrm{ml})$ or the combination of the two agents for $48 \mathrm{~h}$, and then cells were processed for cell cycle analysis $(\mathrm{n}=5)$. DMSO, dimethyl sulfoxide.

USA). Data were analyzed by one-way analysis of variance and Tukey-Kramer multiple comparison test. $\mathrm{P}<0.05$ was considered to indicate a statistically significant difference.

\section{Results}

Anti-proliferation efficacy of cisplatin is enhanced by cardamonin. Our previous study demonstrated that $20 \mu \mathrm{M}$ cardamonin effectively inhibited the activation of mTOR in SKOV3 cells (unpublished data). In the present study, whether $20 \mu \mathrm{M}$ cardamonin enhanced the efficacy of cisplatin was determined. The anti-proliferation effect of cisplatin (1, 2, 4 and $8 \mu \mathrm{g} / \mathrm{ml}$ ) was enhanced by cardamonin in a dose-dependent manner in SKOV3 and A2780 cells (Fig. 1A). Cisplatin at a concentration of $2 \mu \mathrm{g} / \mathrm{ml}$ was selected for the following experiments according to its nephrotoxicity in clinical use. Furthermore, the effect of cardamonin combined with cisplatin $(2 \mu \mathrm{g} / \mathrm{ml})$ on anti-proliferation was more potent in SKOV3 cells compared with that in A2780 cells (cell viability, 34.8 \pm 3.14 vs. $43.1 \pm 3.82 \%$; $\mathrm{P}<0.05$ ). In addition, the clone formation was significantly inhibited by cardamonin combined with cisplatin in SKOV3 and A2780 cells (Fig. 1B).

Cell cycle is arrested by cardamonin and cisplatin at the G2/M phase. It was then determined whether cardamonin was able to enhance cisplatin-induced cell cycle arrest. As presented in Fig. 2, cardamonin and cisplatin induced the accumulation of cells in the $\mathrm{S}$, and $\mathrm{G} 2 / \mathrm{M}$ phase. As expected, cardamonin significantly increased the cisplatin-induced accumulation of cells in the G2/M phase, and the accumulation of cells in G0/G1 phases was significantly reduced (Table I).

Anti-apoptotic proteins are decreased by cardamonin and cisplatin co-administration. Cisplatin-induced apoptosis may be disturbed by the anti-apoptotic proteins. The effect of cardamonin on anti-apoptotic proteins was examined. Cisplatin and cardamonin decreased the protein expression of XIAP and Survivin. Notably, it was demonstrated that combination 
Table I. Effect of cardamonin combined with cisplatin on cell cycle distribution.

\begin{tabular}{lcccc}
\hline & & \multicolumn{3}{c}{ Cell cycle, $\%$} \\
\cline { 3 - 5 } Drug & $\mathrm{n}$ & $\mathrm{G}_{0} / \mathrm{G}_{1}$ & $\mathrm{~S}$ & $\mathrm{G}_{2} / \mathrm{M}$ \\
\hline Control & 5 & $69.96 \pm 3.25$ & $18.50 \pm 2.52$ & $11.54 \pm 3.82$ \\
DMSO & 5 & $70.38 \pm 2.87$ & $19.01 \pm 4.28$ & $10.61 \pm 1.60$ \\
Cisplatin & 5 & $55.99 \pm 1.58^{\mathrm{a}}$ & $22.67 \pm 1.29^{\mathrm{a}}$ & $21.34 \pm 0.68^{\mathrm{a}}$ \\
Cardamonin & 5 & $41.05 \pm 2.14^{\mathrm{a}}$ & $28.54 \pm 2.74^{\mathrm{a}}$ & $30.42 \pm 4.27^{\mathrm{a}}$ \\
Cisplatin + & 5 & $35.33 \pm 2.86^{\mathrm{a}, \mathrm{b}}$ & $31.48 \pm 3.54^{\mathrm{a}, \mathrm{b}}$ & $33.19 \pm 1.16^{\mathrm{a}, \mathrm{b}}$ \\
cardamonin & & & &
\end{tabular}

Effect of cardamonin combined with cisplatin on cell cycle distribution. SKOV3 cells were treated with cardamonin $(20 \mu \mathrm{M})$, cisplatin $(2 \mu \mathrm{g} / \mathrm{ml})$ or the combination of the two agents for $48 \mathrm{~h}$, and then cells were processed for cell cycle analysis $(n=5)$. The ratios of cell cycle distribution were calculated. ${ }^{\mathrm{a}} \mathrm{P}<0.01$ vs. control; ${ }^{\text {b }} \mathrm{P}<0.01$ vs cisplatin. DMSO, dimethyl sulfoxide.

of the two agents significantly reduced the protein expression of Bcl-2, XIAP and Survivin in SKOV3 cells (Fig. 3).

Activation of mTOR and $p 70$ S6K is attenuated by cardamonin . Elevated phosphorylation of mTOR and p70S6K was detected in SKOV3 cells. To examine the effect of mTOR pathway inhibition by cardamonin on ovarian cancer cells, the effect of cardamonin and cisplatin on the phosphorylation of mTOR and p70S6K was examined. No significant effects were observed on the phosphorylation of mTOR and its downstream target (p70S6K) following cisplatin treatment; whereas the activation of mTOR signaling was significantly inhibited by cardamonin, or by the combination of cardamonin and cisplatin (Fig. 4).

\section{Discussion}

Platinum-based chemotherapy is the most commonly used therapeutic approach for ovarian cancer following initial cytoreductive surgery. Although ovarian cancer is highly responsive to cisplatin, there is a substantial risk of emergence of drug resistance, which results in a poorer clinical outcome $(29,30)$. Thus, improving the antitumor efficiency of cisplatin is an essential way for patients with ovarian cancer. A number of flavonoid compounds, including baicalein, apigenin and fisetin may enhance the cytotoxicity of cisplatin in head and neck squamous cell carcinoma, embryonal carcinoma and cervical carcinoma cells (31-33). Epithelial ovarian cancer accounts for almost $80 \%$ of all ovarian cancer cases and is the leading cause of cancer-associated mortality among women (34). Therefore, it was investigated whether cardamonin was able to potentiate the anticancer effect of cisplatin in epithelial ovarian cancer cells, including SKOV3 and A2780 cell lines. The results demonstrated that cardamonin significantly enhanced the anti-proliferative effect of cisplatin in SKOV3 and A2780 cells. The combinatorial effect on anti-proliferation using low concentrations of cisplatin was similar to that of cisplatin in the high concentration, which indicated that cardamonin may decrease the dose of cisplatin required to inhibit the proliferation of ovarian cancer cells, which may be beneficial in gaining clinical efficacy with less adverse effects.

Numerous chemotherapeutic agents, including cisplatin, paclitaxel and fluorouracil, disrupt the cell cycle, which ultimately inhibits cell proliferation $(35,36)$. Cell cycle arrest is a major cellular response to DNA damage. Cisplatin was able to induce $\mathrm{G} 2 / \mathrm{M}$ arrest in ovarian cancer cells $(37,38)$. A previous study demonstrated that cardamonin inhibits cell growth and induces cell cycle arrest at the G2/M phase in colon cancer SW480 cells by suppressing the expression of cyclin D1, and c-myc (39). The results of the present study revealed that cardamonin increased the accumulation of cells in the $\mathrm{S}$ and G2/M phase, and the combination of cardamonin and cisplatin significantly increased the cisplatin-induced G2/M arrest, which indicated that the potential anti-proliferative effect of cardamonin was associated with cell cycle arrest.

The sensitivity of cancer cells to chemotherapeutic drug-induced apoptosis depends on the balance between pro-apoptotic and anti-apoptotic signals, and the inhibition of anti-apoptotic signals has been proposed as a promising strategy to enhance the efficacy of conventional chemotherapeutic agents (40). Several studies have reported that cardamonin is able to inhibit the expression of Bcl-2, Survivin and induce apoptosis $(22,41)$. Furthermore, the mTOR inhibitor CCI-779 decreases the expression of anti-apoptotic proteins and restores the sensitivity of cisplatin-resistant small cell lung cancer cells to cisplatin (42). Therefore, additional study is required to clarify whether cardamonin potentiates the anti-proliferative effect of cisplatin through the anti-apoptotic proteins. The results of the present study revealed that cardamonin significantly enhanced the efficacy of cisplatin by inhibiting the anti-apoptotic signals (Bcl-2, XIAP and Survivin).

mTOR activation is associated with tumor malignancy and poor prognosis in numerous types of human cancer. In addition, mTOR is frequently hyper-activated in cisplatin-insensitive ovarian cancer cells (43). In the present study, it was demonstrated that the activation of mTOR and p70S6K was significantly inhibited by cardamonin, and cardamonin combined with cisplatin. This indicated that cardamonin may prevent the occurrence of cisplatin resistance and reduce the incidence of poor prognosis of patients with ovarian cancer induced by mTOR activation. mTOR inhibition enhances the sensitivity of cisplatin in numerous types of human cancers, including esophageal squamous cell carcinoma, lung cancer and ovarian cancer $(42,44,45)$. RAD001, the analog of rapamycin, in combination with cisplatin was demonstrated to induce a distinct increase in the number of apoptotic cells by downregulating the pro-survival molecules, Bcl-2, Survivin and Cyclin D1 in hepatocellular carcinoma (46), which was consistent with the present results. Therefore, mTOR inhibition by cardamonin provides a strategy for increasing the efficacy of platinum-based treatment for ovarian cancer.

The clinical application of cisplatin is reduced by its dose-dependent toxicity to normal organs, including the liver and kidney. Cardamonin significantly enhanced the anti-proliferative effect of low concentration of cisplatin in ovarian cancer SKOV3 and A2780 cells, which may be useful in reducing the toxicity of cisplatin on normal tissues. 
A

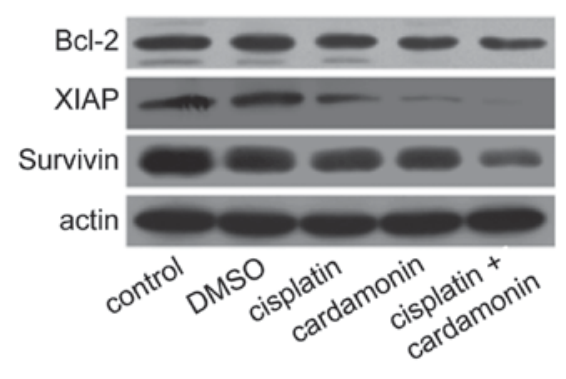

C

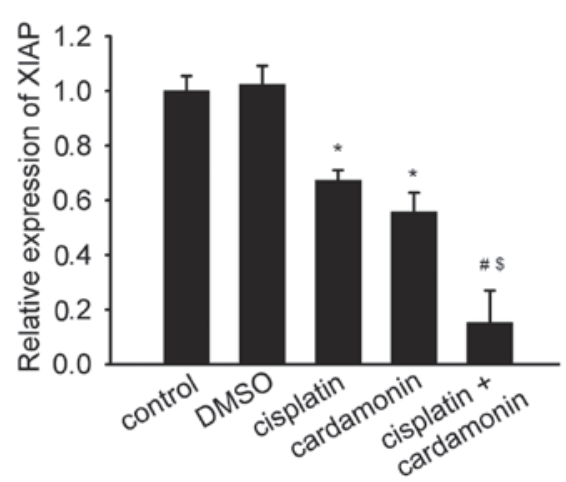

B

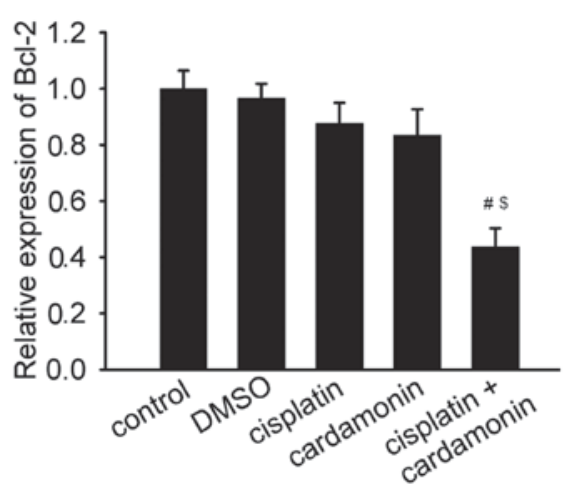

D

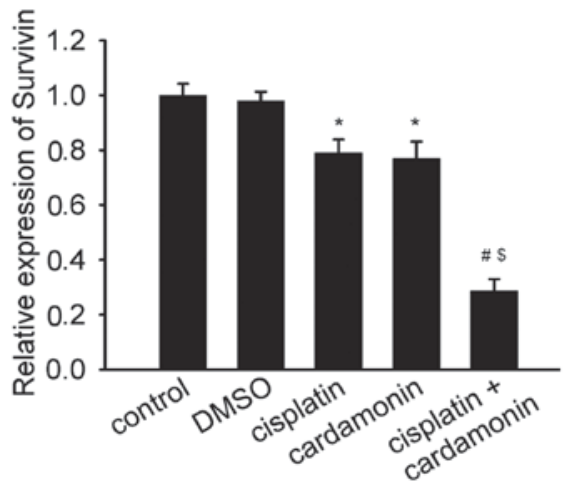

Figure 3. Cardamonin combined with cisplatin decreased the expression of anti-apoptotic proteins. SKOV3 cells were treated with cardamonin (20 $\mu \mathrm{M})$, cisplatin $(2 \mu \mathrm{g} / \mathrm{ml})$ or a combination of the two agents for $48 \mathrm{~h}$. The expression of Bcl-2, XIAP and Survivin was determined by western blot analysis. Actin was used as the loading control (n=3). (A) Representative western blotting protein bands for Bcl-2, XIAP, Survivin and actin. Quantification of (B) Bcl-2, (C) XIAP and (D) Survivin protein expression levels normalized to actin, and compared with control, cisplatin or cardamonin. Data are presented as the mean \pm standard deviation. ${ }^{*} \mathrm{P}<0.05$ vs. control; ${ }^{*} \mathrm{P}<0.01$ vs. cisplatin; ${ }^{\$} \mathrm{P}<0.01$ vs. cardamonin. DMSO, dimethyl sulfoxide; Bcl-2, B cell lymphoma-2; XIAP, X-linked inhibitor of apoptosis protein.
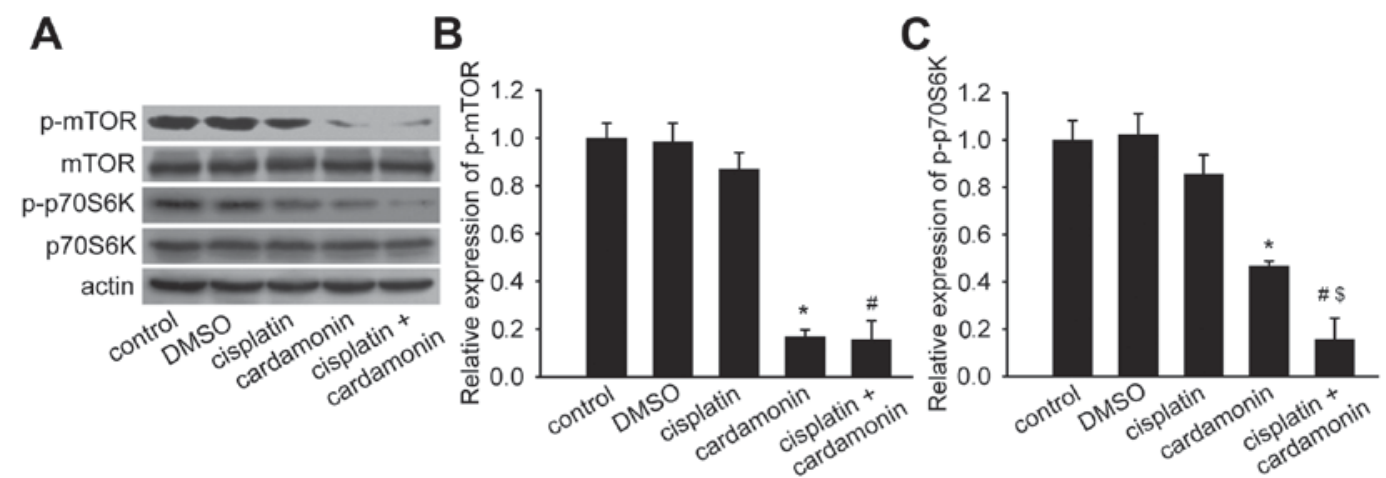

Figure 4. Cardamonin inhibited the activation of mTOR and p70S6K. SKOV3 cells were treated with cardamonin $(20 \mu \mathrm{M})$, cisplatin $(2 \mu \mathrm{g} / \mathrm{ml})$ or the combination of both agents for $48 \mathrm{~h}$. The expression of mTOR, phospho-mTOR (Ser2448), p70S6K and phospho-p70S6K (Thr389) was determined by western blot analysis. Actin was used as the loading control $(n=3)$. (A) Representative western blotting protein bands for mTOR, p-mTOR, p70S6K, p-p70S6K and actin. Quantification of (B) p-mTOR and (C) p-p70S6K protein expression. The relative density ratio of protein was normalized to actin and compared with control, cisplatin or cardamonin. Data are presented as the mean \pm standard deviation. ${ }^{*} \mathrm{P}<0.01$ vs. control; ${ }^{*} \mathrm{P}<0.01$ vs. cisplatin; ${ }^{\circledR} \mathrm{P}<0.01$ vs. cardamonin. $\mathrm{DMSO}$, dimethyl sulfoxide; mTOR, mammalian target of rapamycin; p, phosphorylated; p70S6K, $70 \mathrm{kDa}$ ribosomal protein S6 kinase.

In addition, compared with rapamycin, cardamonin has a number of advantages in vivo, it attenuated the oxidative stress and inflammation to protect against cisplatin-induced nephrotoxicity in rats (24).

In conclusion, these results indicated that the combination of cardamonin and cisplatin is more effective in anti-proliferation compared with the agent used alone in ovarian cancer cells. Cardamonin combined with cisplatin is a promising therapeutic strategy, particularly for patients with
mTOR hyperactivation, which is beneficial for increasing the sensitivity to cisplatin in ovarian cancer.

\section{Acknowledgements}

The present study was supported by the Youth Scientific Foundation of Fujian Provincial Health and Family Planning Commission (grant no. 2013-1-11) and the Natural Science Foundation of Fujian Province (grant nos. 2015J01368 and 2016J01492), China. 


\section{References}

1. Siegel R, Naishadham D and Jemal A: Cancer statistics, 2013 CA Cancer J Clin 63: 11-30, 2013.

2. Qian X, Qin J, Pan S, Li X, Pan Y and Ma S: Maintenance therapy in ovarian cancer with targeted agents improves PFS and OS: A systematic review and meta-analysis. PLoS One 10: e0139026, 2015.

3. Chen J, Solomides C, Parekh H, Simpkins F and Simpkins H: Cisplatin resistance in human cervical, ovarian and lung cancer cells. Cancer Chemother Pharmacol 75: 1217-1227, 2015.

4. Wang $\mathrm{J}$ and $\mathrm{Wu}$ GS: Role of autophagy in cisplatin resistance in ovarian cancer cells. J Biol Chem 289: 17163-17173, 2014.

5. Makin G and Dive C: Apoptosis and cancer chemotherapy. Trends Cell Biol 11: S22-S26, 2001.

6. Shaltouki A, Freer M, Mei Y and Weyman CM: Increased expression of the pro-apoptotic Bcl2 family member PUMA is required for mitochondrial release of cytochrome $\mathrm{C}$ and the apoptosis associated with skeletal myoblast differentiation. Apoptosis 12 2143-2154, 2007.

7. Scott FL, Denault JB, Riedl SJ, Shin H, Renatus M and Salvesen GS: XIAP inhibits caspase-3 and -7 using two binding sites: Evolutionarily conserved mechanism of IAPs. EMBO J 24 645-655, 2005

8. Zumbrägel FK, Machtens DA, Curth U, Lüder CG, Reubold TF and Eschenburg S: Survivin does not influence the anti-apoptotic action of XIAP on caspase-9. Biochem Biophys Res Commun 482: 530-535, 2017.

9. Yang Q, Wang H, Chen S, Lan X, Xiao H, Shi H and Ma Y: Fiber-optic-based micro-probe using hexagonal 1-in-6 fiber configuration for intracellular single-cell $\mathrm{pH}$ measurement. Anal Chem 87: 7171-7179, 2015.

10. Zhang Z, Xie Z, Sun G, Yang P, Li J, Yang H, Xiao S, Liu Y, Qiu H, Qin L, et al: Reversing drug resistance of cisplatin by hsp90 inhibitors in human ovarian cancer cells. Int J Clin Exp Med 8: 6687-6701, 2015.

11. Zhao WJ, Deng BY, Wang XM, Miao Y and Wang JN XIAP associated factor 1 (XAF1) represses expression of $\mathrm{X}$-linked inhibitor of apoptosis protein (XIAP) and regulates invasion, cell cycle, apoptosis, and cisplatin sensitivity of ovarian carcinoma cells. Asian Pac J Cancer Prev 16: 2453-2458, 2015

12. Mabuchi S, Kawase C, Altomare DA, Morishige K, Sawada K, Hayashi M, Tsujimoto M, Yamoto M, Klein-Szanto AJ, Schilder RJ, et al: mTOR is a promising therapeutic target both in cisplatin-sensitive and cisplatin-resistant clear cell carcinoma of the ovary. Clin Cancer Res 15: 5404-5413, 2009.

13. Xu S, Fu GB, Tao Z, OuYang J, Kong F, Jiang BH, Wan X and Chen K: MiR-497 decreases cisplatin resistance in ovarian cance cells by targeting mTOR/P70S6K1. Oncotarget 6: 26457-26471, 2015.

14. Feng $\mathrm{X}$, Li L, Jiang $\mathrm{H}$, Jiang $\mathrm{K}$, Jin $\mathrm{Y}$ and Zheng J: Dihydroartemisinin potentiates the anticancer effect of cisplatin via mTOR inhibition in cisplatin-resistant ovarian cancer cells: Involvement of apoptosis and autophagy. Biochem Biophys Res Commun 444: 376-381, 2014.

15. Peng DJ, Wang J, Zhou JY and Wu GS: Role of the Akt/mTOR survival pathway in cisplatin resistance in ovarian cancer cells Biochem Biophys Res Commun 394: 600-605, 2010.

16. Wu H, Zhao Y, Mu X, Wu H, Chen L, Liu W, Mu Y, Liu J and Wei X: A silica-polymer composite nano system for tumor-targeted imaging and p53 gene therapy of lung cancer. J Biomater Sci Polym Ed 26: 384-400, 2015.

17. Mabuchi S, Hisamatsu T, Kawase C, Hayashi M, Sawada K, Mimura K, Takahashi K, Takahashi T, Kurachi H and Kimura T: The activity of trabectedin as a single agent or in combination with everolimus for clear cell carcinoma of the ovary. Clin Cancer Res 17: 4462-4473, 2011.

18. Li Y, Qin Y, Yang C, Zhang H, Li Y, Wu B, Huang J, Zhou X, Huang B, Yang K and Wu G: Cardamonin induces ROS-mediated $\mathrm{G} 2 / \mathrm{M}$ phase arrest and apoptosis through inhibition of NF- $\mathrm{KB}$ pathway in nasopharyngeal carcinoma. Cell Death Dis 8: e3024, 2017.

19. Zhang J, Sikka S, Siveen KS, Lee JH, Um JY, Kumar AP, Chinnathambi A, Alharbi SA, Basappa, Rangappa KS, et al Cardamonin represses proliferation, invasion, and causes apoptosis through the modulation of signal transducer and activator of transcription 3 pathway in prostate cancer. Apoptosis 22: 158-168, 2017
20. Shrivastava S, Jeengar MK, Thummuri D, Koval A, Katanaev VL, Marepally S and Naidu VGM: Cardamonin, a chalcone, inhibits human triple negative breast cancer cell invasiveness by downregulation of $\mathrm{Wnt} / \beta$-catenin signaling cascades and reversal of epithelial-mesenchymal transition. Biofactors 43 : 152-169, 2017.

21. Kim YJ, Kang KS, Choi KC and Ko H: Cardamonin induces autophagy and an antiproliferative effect through JNK activation in human colorectal carcinoma HCT116 cells. Bioorg Med Chem Lett 25: 2559-2564, 2015.

22. Wu N, Liu J, Zhao X, Yan Z, Jiang B, Wang L, Cao S, Shi D and Lin X: Cardamonin induces apoptosis by suppressing STAT3 signaling pathway in glioblastoma stem cells. Tumour Biol 36: 9667-9676, 2015.

23. Jia D, Tan Y, Liu H, Ooi S, Li L, Wright K, Bennett S, Addison CL and Wang L: Cardamonin reduces chemotherapy-enriched breast cancer stem-like cells in vitro and in vivo. Oncotarget 7: 771-785, 2016.

24. El-Naga RN: Pre-treatment with cardamonin protects against cisplatin-induced nephrotoxicity in rats: Impact on NOX-1, inflammation and apoptosis. Toxicol Appl Pharmacol 274: 87-95, 2014.

25. Tang Y, Fang Q, Shi D, Niu P, Chen Y and Deng J: mTOR inhibition of cardamonin on antiproliferation of A549 cells is involved in a FKBP12 independent fashion. Life Sci 99: 44-51, 2014.

26. Niu PG, Zhang YX, Shi DH, Liu Y, Chen YY and Deng J: Cardamonin inhibits metastasis of lewis lung carcinoma cells by decreasing mTOR activity. PLoS One 10: e0127778, 2015.

27. Xue ZG, Niu PG, Shi DH, Liu Y, Deng J and Chen YY: Cardamonin inhibits angiogenesis by mTOR downregulation in SKOV3 cells. Planta Med 82: 70-75, 2016.

28. Mabuchi S, Altomare DA, Cheung M, Zhang L, Poulikakos PI, Hensley HH, Schilder RJ, Ozols RF and Testa JR: RAD001 inhibits human ovarian cancer cell proliferation, enhances cisplatin-induced apoptosis, and prolongs survival in an ovarian cancer model. Clin Cancer Res 13: 4261-4270, 2007.

29. González-Martín A, Sánchez-Lorenzo L, Bratos R, Márquez R and Chiva L: First-line and maintenance therapy for ovarian cancer: Current status and future directions. Drugs 74: 879-889, 2014.

30. Mould T: An overview of current diagnosis and treatment in ovarian cancer. Int J Gynecol Cancer 22 (Suppl 1): S2-S4, 2012.

31. Chan LP, Chou TH, Ding HY, Chen PR, Chiang FY, Kuo PL and Liang CH: Apigenin induces apoptosis via tumor necrosis factor receptor- and Bcl-2-mediated pathway and enhances susceptibility of head and neck squamous cell carcinoma to 5-fluorouracil and cisplatin. Biochim Biophys Acta 1820: 1081-1091, 2012.

32. Tripathi R, Samadder T, Gupta S, Surolia A and Shaha C: Anticancer activity of a combination of cisplatin and fisetin in embryonal carcinoma cells and xenograft tumors. Mol Cancer Ther 10: 255-268, 2011.

33. Wang Y, Wang Q, Zhang S, Zhang Y and Tao L: Baicalein increases the cytotoxicity of cisplatin by enhancing gap junction intercellular communication. Mol Med Rep 10: 515-521, 2014.

34. Sankaranarayanan R and Ferlay J: Worldwide burden of gynaecological cancer: The size of the problem. Best Pract Res Clin Obstet Gynaecol 20: 207-225, 2006.

35. Elias ST, Borges GA, Rêgo DF, E Silva LF, Avelino S DE Matos Neto JN, Simeoni LA and Guerra EN: Combined paclitaxel, cisplatin and fluorouracil therapy enhances ionizing radiation effects, inhibits migration and induces G0/G1 cell cycle arrest and apoptosis in oral carcinoma cell lines. Oncol Lett 10: 1721-1727, 2015.

36. Li Y, Li W, Deng W, Gan Y, Wu K and Sun J: Synergistic anti-proliferative and pro-apoptotic activities of $5 \mathrm{~F}$ and cisplatin in human non-small cell lung cancer NCI-H23 cells. Oncol Lett 14: 5347-5353, 2017.

37. Chen X, Gong L, Ou R, Zheng Z, Chen J, Xie F, Huang X, Qiu J, Zhang W, Jiang Q, et al: Sequential combination therapy of ovarian cancer with cisplatin and $\gamma$-secretase inhibitor MK-0752. Gynecol Oncol 140: 537-544, 2016.

38. Taylor-Harding B, Orsulic S, Karlan BY and Li AJ: Fluvastatin and cisplatin demonstrate synergistic cytotoxicity in epithelial ovarian cancer cells. Gynecol Oncol 119: 549-556, 2010.

39. Park S, Gwak J, Han SJ and Oh S: Cardamonin suppresses the proliferation of colon cancer cells by promoting $\beta$-catenin degradation. Biol Pharm Bull 36: 1040-1044, 2013

40. Wang H, Zhang Z, Wei X and Dai R: Small-molecule inhibitor of Bcl-2 (TW-37) suppresses growth and enhances cisplatin-induced apoptosis in ovarian cancer cells. J Ovarian Res 8: 3, 2015. 
41. Yadav VR, Prasad S and Aggarwal BB: Cardamonin sensitizes tumour cells to TRAIL through ROS- and CHOP-mediated up-regulation of death receptors and down-regulation of survival proteins. Br J Pharmacol 165: 741-753, 2012.

42. Wangpaichitr M, Wu C, You M, Kuo MT, Feun L, Lampidis T and Savaraj N: Inhibition of mTOR restores cisplatin sensitivity through down-regulation of growth and anti-apoptotic proteins. Eur J Pharmacol 591: 124-127, 2008.

43. Aide N, Kinross K, Cullinane C, Roselt P, Waldeck K, Neels O, Dorow D, McArthur G and Hicks RJ: 18F-FLT PET as a surrogate marker of drug efficacy during mTOR inhibition by everolimus in a preclinical cisplatin-resistant ovarian tumor model. J Nucl Med 51: 1559-1564, 2010
44. Hou G, Yang S, Zhou Y, Wang C, Zhao W and Lu Z: Targeted inhibition of mTOR signaling improves sensitivity of esophageal squamous cell carcinoma cells to cisplatin. J Immunol Res 2014: 845763, 2014

45. Cai Y, Tan X, Liu J, Shen Y, Wu D, Ren M, Huang P and $\mathrm{Yu}$ D: Inhibition of PI3K/Akt/mTOR signaling pathway enhances the sensitivity of the SKOV3/DDP ovarian cancer cell line to cisplatin in vitro. Chin J Cancer Res 26: 564-572, 2014

46. Tam KH, Yang ZF, Lau CK, Lam CT, Pang RW and Poon RT: Inhibition of mTOR enhances chemosensitivity in hepatocellular carcinoma. Cancer Lett 273: 201-209, 2009. 